\title{
Continuous On-line Leaching to Evaluate the Effect of Toasting on Bioaccessibility and Pb Source Apportionment of Alternative Breads
}

\author{
Alastair Kierulf, ${ }^{\mathrm{a}}$ Cameron Pytyck, ${ }^{\mathrm{a}}$ and Diane Beauchemin ${ }^{\mathrm{a}, *}$ \\ a'Department of Chemistry, 90 Bader Lane, Queen's University, Kingston, Ontario, K7L 3N6, Canada \\ Received: August 01, 2021; Revised: September 18, 2021; Accepted: September 18, 2021; Available online: September 27, 2021.
}

DOI: 10.46770/AS.2021.724

ABSTRACT: With the increasing popularity of alternative breads, investigating their health benefits and risks is vitally important. The bioaccessibility of potentially toxic elements (PETs) in these breads could indicate a potential risk to consumers. The continuous online leaching method (COLM) involves the sequential leaching of a mini-column of food by artificial saliva, gastric juice, and intestinal fluid with real time monitoring of elements being released. Because the dissolution equilibrium is shifted to the right from continuous exposure to fresh reagent, it assesses bioaccessibility in three gastrointestinal matrices in less than $30 \mathrm{~min}$ and includes valuable kinetic extraction information. In this study, a gluten-free (GF) and a rye bread were analyzed for $\mathrm{As}, \mathrm{Cd}$, and $\mathrm{Pb}$ before and after toasting. Toasting lowered all PTE concentrations by a factor of 1.5 (As in rye bread) to $2.5(\mathrm{Cd}$ in rye bread). Most of the PTEs present were bioaccessible whether the bread was toasted or not. In the case of As, a significant portion is in the form of As(III) and As(V). COLM analysis allowed for $\mathrm{Pb}$ sourcing, revealing two potential sources of $\mathrm{Pb}$ being released separately in gastric juice from rye bread based on their significantly different ${ }^{206} \mathrm{~Pb} /{ }^{207} \mathrm{~Pb}$ and ${ }^{208} \mathrm{~Pb} /{ }^{206} \mathrm{~Pb}$ isotope ratios. Comparison with $\mathrm{Pb}$ ratios reported in previous literature revealed that some of the gastric-mobile $\mathrm{Pb}$ in rye bread came from the $\mathrm{Pb}$ historically added to gasoline in North America. This source completely vanished upon toasting rye

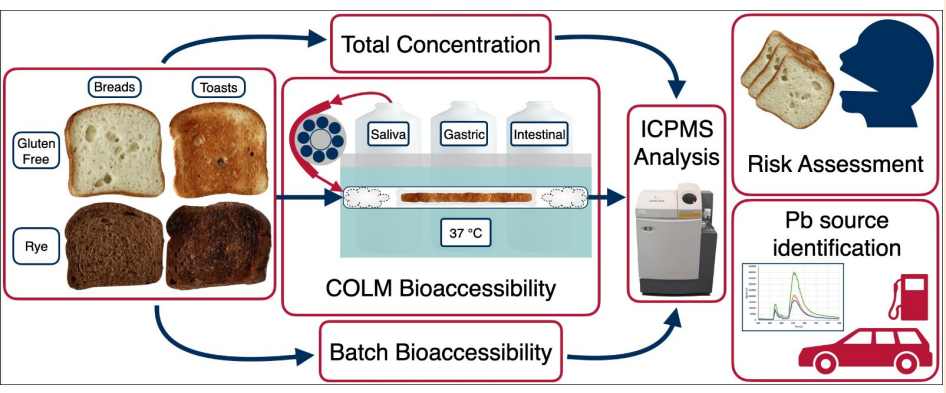
bread.

\section{INTRODUCTION}

Bread is a common food staple across cultures and around the world. In North America, bread generated over USD15 billion in 2020, and retail sales in Europe were approximately USD100 billion in 2020. ${ }^{1,2}$ Although bread made from wheat is the most common variety sold in North America, gluten-free (GF) alternatives have been growing in popularity. ${ }^{3}$ Many people with celiac disease, an autoimmune disease in which gluten damages the small intestine, seek out these GF alternatives. Celiac disease is highly individualized, with certain treatment options including adherence to a strict GF diet. In Canada, approximately $1.9 \%$ of Canadians avoid dietary gluten. ${ }^{4}$ In the United States, approximately $30 \%$ of the population have adopted a GF diet, while it is estimated that $1 \%$ of the population actually has celiac disease (and fewer individuals have been diagnosed). ${ }^{5}$ Despite this, there is little evidence to suggest that a GF diet is better for the health of a non-celiac individual and may even have some adverse health effects, such as improper nutrition, financial strain, and social and psychological effects. ${ }^{6-8}$

With most North Americans turning to alternative breads, it is important to assess the potential risks involved in eating staples from alternative sources. Grains, such as rice, rye, and wheat, all contain appreciable levels of potentially toxic elements (PTEs). ${ }^{9-11}$ Because some GF breads use rice flour as the main source of starch, it is important to assess whether the PTEs from these alternative grains are transferred into the breads and are 
made accessible to the body during digestion.

When dealing with PTEs in foods, a key component is the bioaccessibility of the PTE, which is the amount leached out of food by gastrointestinal matrices during digestion. It can indicate the maximum possible bioavailable amount, which is the amount of PTE absorbed into the blood. Unfortunately, in vivo bioavailability studies are time-consuming, expensive, and require animal subjects. ${ }^{12}$ To overcome these barriers, several in vitro bioaccessibility methods have been developed and validated against in vivo bioavailability methods. ${ }^{13-15}$ When considering the bioaccessibility of PTEs, it is important to incorporate a risk assessment to determine if the bioaccessible concentrations are of concern. Inductively coupled plasma mass spectrometry (ICPMS) is widely used for the analysis of samples in a risk assessment for PTEs in foods, because it offers a large linear dynamic range, low detection limits, and high sensitivity. ${ }^{16}$

When conducting a human health risk assessment, tolerable daily intake (TDI) levels are needed to characterize the adult daily maximum limit of consumption for each PTE. Health Canada has TDIs for $\mathrm{Cd}\left(0.0008 \mathrm{mg} \mathrm{kg}\right.$-bodyweight $\left.[\mathrm{bw}]^{-1} \mathrm{day}^{-1}\right)$ and $\mathrm{Pb}\left(0.0005 \mathrm{mg} \mathrm{kg}^{-b^{-1}}\right.$ day $\left.^{-1}\right),{ }^{17}$ and the Ontario Ministry of the Environment (OME) has a TDI for As $\left(0.0003 \mathrm{mg} \mathrm{kg-bw}^{-1}\right.$ day $\left.^{-1}\right),{ }^{18}$ which is within the benchmark dose lower confidence limit proposed by the European Food Safety Authority. ${ }^{19}$ Using these values and an average adult bw of $70.7 \mathrm{~kg}$, a preliminary risk assessment could be conducted to determine the daily serving size of each of these alternative breads (e.g., how many slices) that could place an average adult above their TDI limits.

An alternative to the previously mentioned batch bioaccessibility methods is the COLM, which places the sample in a mini-column and uses a peristaltic pump to introduce each artificial gastrointestinal matrix into the sample sequentially. The COLM was applied to a certified reference material of rice flour to verify recovery (i.e. that the sum of analyte concentrations leached and left in the residue matched the certified total concentration). ${ }^{20}$ It has been employed to assess the bioaccessibility of a number of PTEs in foods such as rice, ${ }^{20-22}$ fish, ${ }^{23,24}$ corn bran, ${ }^{25}$ wheat, ${ }^{10,11}$ and white and whole-wheat breads. ${ }^{26}$ In all cases, recovery was verified when the sum of concentrations leached and in the residues was compared to the total concentration measured after a separate total digestion. The artificial matrices were prepared to closely simulate the gastrointestinal conditions of a fasting individual, because fasting occurs when the $\mathrm{HCl}$ concentration is the highest. Both the artificial gastrointestinal matrices and the mini-column were submerged in a temperature-controlled water bath set to $37^{\circ} \mathrm{C}$ to mimic the average basal temperature of the body. After exiting the column, the matrix is sent directly to the ICPMS instrument to reduce sample handling and the potential for contamination. The signals produced during continuous online leaching are transient time-resolved peaks, which provide real-time information on the leaching kinetics of PTEs. This allows for a reduction in leaching time, and the results for all three gastrointestinal matrices were obtained in only $25 \mathrm{~min}$. This is a significant improvement over conventional batch methods that can incubate samples in gastric juice alone for up to $2 \mathrm{~h}$ before analysis. Thus, a full bioaccessibility analysis using all three gastrointestinal matrices can take over $4 \mathrm{~h}$ with some conventional batch methods. Additionally, many current bioaccessibility studies have omitted some important biological factors that should be considered. For example, many studies omit saliva as a gastrointestinal matrix even though it has been shown to have significant leaching capabilities in rice, seafood, corn bran, wheat, as well as white and whole wheat bread samples. ${ }^{20-26}$ These are important factors to consider if the bioaccessibility study is to mimic the human body conditions as much as possible. Saliva is indeed the first gastrointestinal matrix samples are exposed to, and more soluble PTEs may have significant leaching into saliva. Valuable information about how bioaccessible PTEs are may thus be lost by omitting saliva.

Because the COLM affords real-time leaching data, an assessment of the elution profiles for certain PTEs could also be performed to determine the geochemical sources of elements. Analytes that elute in two separate phases may have different geochemical origins. ${ }^{27}$ One recent study in particular found for the first time that plotting the leaching profiles of one element versus another could potentially reveal different sources of certain elements. ${ }^{28}$ This can then be further investigated through isotope ratio analysis. The $\mathrm{Pb}$ isotope ratio analysis is a commonly used technique identifying geogenic (natural) sources and anthropogenic (human) sources of $\mathrm{Pb} .{ }^{29-32} \mathrm{An}$ important source of $\mathrm{Pb}$ has been the historic use of tetraethyllead (TEL) as an additive to gasoline. Beginning in the 1920s, TEL was used as an antiknock agent for motor fuels and was used globally throughout the twentieth century. Because of this widespread use and unique $\mathrm{Pb}$ isotopic ratio, many studies of sediments, soils, animals, and even urban honeys have reported TEL source apportionment. ${ }^{33-36}$

To follow up on the recent analysis of white and whole-wheat breads using the COLM,${ }^{26}$ this study will investigate for the first time the effect of toasting locally available alternative breads on PTE release and bioaccessibility. In addition, it makes use of the time-resolved nature of the COLM, which gives further dynamic leaching information, and allows for $\mathrm{Pb}$ source apportionment and isotope ratio analysis. This enabled the characterization of sources of potential $\mathrm{Pb}$ contamination in these breads. With the global increase in the number of alternative breads, determining their PTE composition, bioaccessibility, and contamination sources will provide important information for industries, regulatory bodies, and consumer's health. 


\section{EXPERIMENTAL}

Sample preparation. A loaf of GF bread and a loaf of rye bread were purchased from a local grocery store in Kingston, ON, Canada. Two slices of each loaf were air-dried at room temperature and two were well toasted in a conventional home toaster (at $250-270{ }^{\circ} \mathrm{C}$ ). For future analyses, the slices were combined and ground to a fine powder using a food processor and then refrigerated $\left(\leq 5^{\circ} \mathrm{C}\right)$.

For the COLM mini-columns, polytetrafluoroethylene (PTFE) tubing with an inner diameter of $1 / 8^{\prime \prime}(3.17 \mathrm{~mm})$ and outer diameter of 3/16" (4.76 mm) was cut into $10 \mathrm{~cm}$ lengths. Glass wool was cleaned overnight in $10 \%(\mathrm{v} / \mathrm{v}) \mathrm{HNO}_{3}$, soaked in artificial saliva, air-dried, and then stored in an airtight bag. Five replicate mini-columns were prepared by rolling a $0.25 \mathrm{~g}$ sample in glass wool and inserting it into the tubing. A glass wool "plug" was inserted at each end to secure the sample in place. Three blank mini-columns were prepared by inserting glass wool without any samples.

Reagents. The $\mathrm{HCl}$ (ACS grade; Fisher Scientific, Ottawa, ON, Canada) and $\mathrm{HNO}_{3}$ (ACS grade; Fisher Scientific) used throughout this experiment were sub-boiled in-house using a DST-1000 sub-boiling distillation system (Savillex, Minnetonka, USA). Doubly deionized water (DDW) was purified using an Arium Pro UV/DI water purification system (Sartorius Stedim Biotech, Göttingen, Germany).

Artificial saliva, gastric, and intestinal matrices were prepared following procedures in previous studies. ${ }^{10,26}$ Saliva was prepared without digestion enzyme by mixing $6.8 \mathrm{~g} \mathrm{KH}_{2} \mathrm{PO}_{4}$ (ACS grade; Fisher Scientific, NJ, USA) and $77 \mathrm{~mL}$ of $0.2 \mathrm{~mol} \mathrm{~L}^{-1} \mathrm{NaOH}$ (ACS grade; BioShop, Burlington, ON, Canada), and then diluting to $1 \mathrm{~L}$ using DDW. A pH of 6.5 was maintained by adding $0.2 \mathrm{molL}^{-1} \mathrm{NaOH}$ as needed. Gastric juice was prepared by combining $2.0 \mathrm{~g} \mathrm{NaCl}$ (ACS grade; BioShop), $3.2 \mathrm{~g}$ pepsin (USP grade; Sigma-Aldrich, St. Louis, MO, USA), and 7.0 mL sub-boiled $\mathrm{HCl}$ and diluting to $1 \mathrm{~L}$ with a $\mathrm{pH}$ of 1.2 with DDW. Intestinal juice was prepared with $6.8 \mathrm{~g} \mathrm{KH}_{2} \mathrm{PO}_{4}, 10 \mathrm{~g}$ pancreatin (a mixture of amylase, lipase, and protease) (USP grade; Sigma-Aldrich) and $77 \mathrm{~mL} 0.2 \mathrm{molL}^{-1} \mathrm{NaOH}$, diluted to $1 \mathrm{~L}$ with DDW, and adjusted to $\mathrm{pH} 6.8$ using $\mathrm{NaOH}$.

Residual and total analysis digestions were conducted with $0.75 \mathrm{~mL} \mathrm{H} \mathrm{H}_{2} \mathrm{O}_{2}$ (ACS grade; Sigma-Aldrich) and $2.5 \mathrm{~mL}$ sub-boiled $\mathrm{HNO}_{3}$. Multi-element standard solutions were matrix-matched and prepared using 10,000 $\mathrm{mgL}^{-1}$ elemental standards (SCP Science, Baie d'Urfé, QC, Canada).

Total digestion. Total digestion of the samples was performed to check for mass balance by comparing the sum of bioaccessible portions and that left in the residue with the total amount present in the original sample. The digestion procedure was previously validated with a rice flour $\mathrm{CRM}^{20}$ and used for wheat ${ }^{11}$ and bread samples. ${ }^{26}$ Six replicate aliquots of $1 \mathrm{~g}$ samples were digested in
PTFE digestion vessels (Savillex) with $2.5 \mathrm{~mL}$ sub-boiled $\mathrm{HNO}_{3}$ and $0.75 \mathrm{~mL} \mathrm{H}_{2} \mathrm{O}_{2}$ using a hot plate at $50^{\circ} \mathrm{C}$ for $2 \mathrm{~h}$. The resulting solution was diluted to $25 \mathrm{~mL}$ with DDW and analyzed for $\mathrm{As}, \mathrm{Cd}$, and $\mathrm{Pb}$ concentrations using ICPMS.

Batch bioaccessibility extraction. Five replicate aliquots of $1 \mathrm{~g}$ samples were placed into Falcon tubes, and $12 \mathrm{~mL}$ artificial saliva was added to each tube. Each sample was shaken for 10 min at $37^{\circ} \mathrm{C}$ and centrifuged for $15 \mathrm{~min}$ at $4100 \mathrm{rpm}$ at $3{ }^{\circ} \mathrm{C}$. The supernatant was decanted for analysis and $12 \mathrm{~mL}$ artificial gastric juice was added. This was shaken for $2 \mathrm{~h}$ at $37^{\circ} \mathrm{C}$, centrifuged for $15 \mathrm{~min}$ at $4100 \mathrm{rpm}$ at $3{ }^{\circ} \mathrm{C}$, and decanted. This process was repeated with $12 \mathrm{~mL}$ artificial intestinal juice $(2 \mathrm{~h}$ shaking at $37^{\circ} \mathrm{C} ; 15$ min centrifuge, $4100 \mathrm{rpm}, 3^{\circ} \mathrm{C}$ ) to mimic a typical in vivo digestion environment. After leaching, the residual samples from all three matrices were fully digested according to the total digestion procedure to determine the amount of PTEs that were not bioaccessible and check recovery. The gastrointestinal supernatants were analyzed using ICPMS with a $5 \mu \mathrm{g} \mathrm{\textrm {L } ^ { - 1 }}$ In internal standard added online using a Y-connector and matrix-matched external calibration. There was no dilution or digestion of the extracts prior to analysis. Care was also taken to analyze the extracts within $24 \mathrm{~h}$ of collection to minimize analyte loss.

COLM. Each prepared mini-column was attached like a "sample loop" on a flow injection (FI) valve so as to allow a change of mini-column (in the "load" position) without interrupting the flow of reagent to the ICPMS instrument. The mini-column was submerged in a $37{ }^{\circ} \mathrm{C}$ water bath and each artificial gastrointestinal matrix (also maintained at $37^{\circ} \mathrm{C}$ ) was sequentially pumped through it. The eluents from the column were directly nebulized into the ICPMS instrument. After elution with all three matrices, the residual mini-column contents were digested according to the total digestion procedure, to determine the amount of non-bioaccessible PTEs and check recovery.

For COLM calibration, external calibration was performed using matrix-matched standards and a FI manifold. Each standard was prepared in the appropriate matrix and introduced through a $100 \mu \mathrm{L}$ injection loop. Because no signal drift was observed during the online analyses, no internal standardization was necessary.

Instrumentation. All analyses were conducted on a Varian 820MS quadrupole-based ICPMS instrument equipped with collision reaction interface (CRI), Ni sampler cone with a 0.9 $\mathrm{mm}$ diameter opening, and $\mathrm{Ni}$ skimmer cone with a $0.4 \mathrm{~mm}$ diameter opening. Samples were introduced into a T2100 Burgener nebulizer and a Peltier-cooled Scott-type double-pass spray chamber maintained at $3{ }^{\circ} \mathrm{C}$. The skimmer cone was equipped with $\mathrm{CRI}$ and used at the previously determined optimum flow rate of $85 \mathrm{~mL} \mathrm{~min}{ }^{-1} \mathrm{H}_{2}$ because sample matrices were similar to those in previous work. ${ }^{21,26}$ Torch alignment was conducted each day using a $5 \mathrm{\mu L}^{-1}$ tuning solution with $\mathrm{Be}, \mathrm{Mg}$, 
$\mathrm{Co}, \mathrm{In}, \mathrm{Ce}, \mathrm{Pb}$, and $\mathrm{Ba}$ in $1 \%$ nitric acid. Batch bioaccessibility and total concentration data were acquired in steady-state mode with $5 \mathrm{~s}$ integration, whereas online data were acquired in time-resolved mode with three points per peak, one scan per replicate, and a dwell time of $80 \mathrm{~ms}$. All other pertinent operating conditions are summarized in Table S1.

Speciation analysis of saliva and gastric juice leachates from GF toast. Three replicate mini-columns of GF toast were prepared as previously described and eluents were collected off-line for the saliva and gastric juice. These phases were then separately analyzed by ion chromatography with a previously optimized gradient elution program. ${ }^{21}$ Briefly, the chromatography setup consisted of an IonPac AG7 (Dionex, Oakville, Canada) guard column and a $25 \mathrm{~cm}$ long, $4 \mathrm{~mm}$ diameter IonPac AS7 anion exchange analytical column (Dionex) maintained at $20^{\circ} \mathrm{C}$. Gradient elution started with $0.5 \mathrm{mmol} / \mathrm{L}$ $\mathrm{HNO}_{3}$ and $1 \% \mathrm{MeOH}$ for $3 \mathrm{~min}$ to separate As(III), MMA (monomethyl arsenic acid), and DMA (dimethyl arsenic acid), then switched to $50 \mathrm{mmol} / \mathrm{L} \mathrm{HNO}_{3}$ and $1 \% \mathrm{MeOH}$ for $2.5 \mathrm{~min}$ to elute As (V). The flow rate was $1.5 \mathrm{~mL} / \mathrm{min}$ and $25 \mu \mathrm{L}$ injections were done. Because direct injection of saliva extracts resulted in co-elution of As(III) and MMA, a five-fold dilution in DDW was performed to achieve adequate resolution of the two peaks. ${ }^{22}$ The eluents were fed into the nebulizer of the ICPMS instrument with a $0.17 \mathrm{~mm}$ inner diameter, $40 \mathrm{~cm}$ long piece of PTFE tubing. Additionally, the column was rinsed for $2 \mathrm{~h}$ using $0.5 \mathrm{mM}$ $\mathrm{HNO}_{3}$ to avoid peak broadening, and stabilization with $0.5 \mathrm{mM}$ $\mathrm{HNO}_{3}$ was performed for $20 \mathrm{~min}$ prior to each series of chromatographic separations on a given day. Data acquisition parameters were the same as for the time-resolved mode of the COLM.

\section{RESULTS AND DISCUSSION}

Effect of toasting on total and bioaccessible concentrations of As, Cd, and Pb. Bread and toasted samples were analyzed on the same day and using the same calibration to enable their direct comparison. The total concentration, batch method phases of saliva, gastric, intestinal, and residual and COLM phases of saliva, gastric, intestinal, and residual (all in $\mathrm{mg} \mathrm{kg}^{-1}$ ) for the GF and rye bread and toast samples are presented in Fig. 1. The corresponding data can be found in Table S2. A Student's t-test at the $95 \%$ confidence interval (included in Table S2) verified complete recovery for all COLM and batch samples, as there was no statistically significant difference between the sums of the different fractions and the concentrations measured after total digestion of separate sample aliquots. This confirmed that matrix-matched external calibration provided accurate results and that internal standardization was not necessary with the COLM. Toasting lowered all PTE concentrations by a factor of 1.5 (As in rye samples) to 2.5 (Cd in rye samples). This may be caused by the complexation and volatilization of some elements, which can
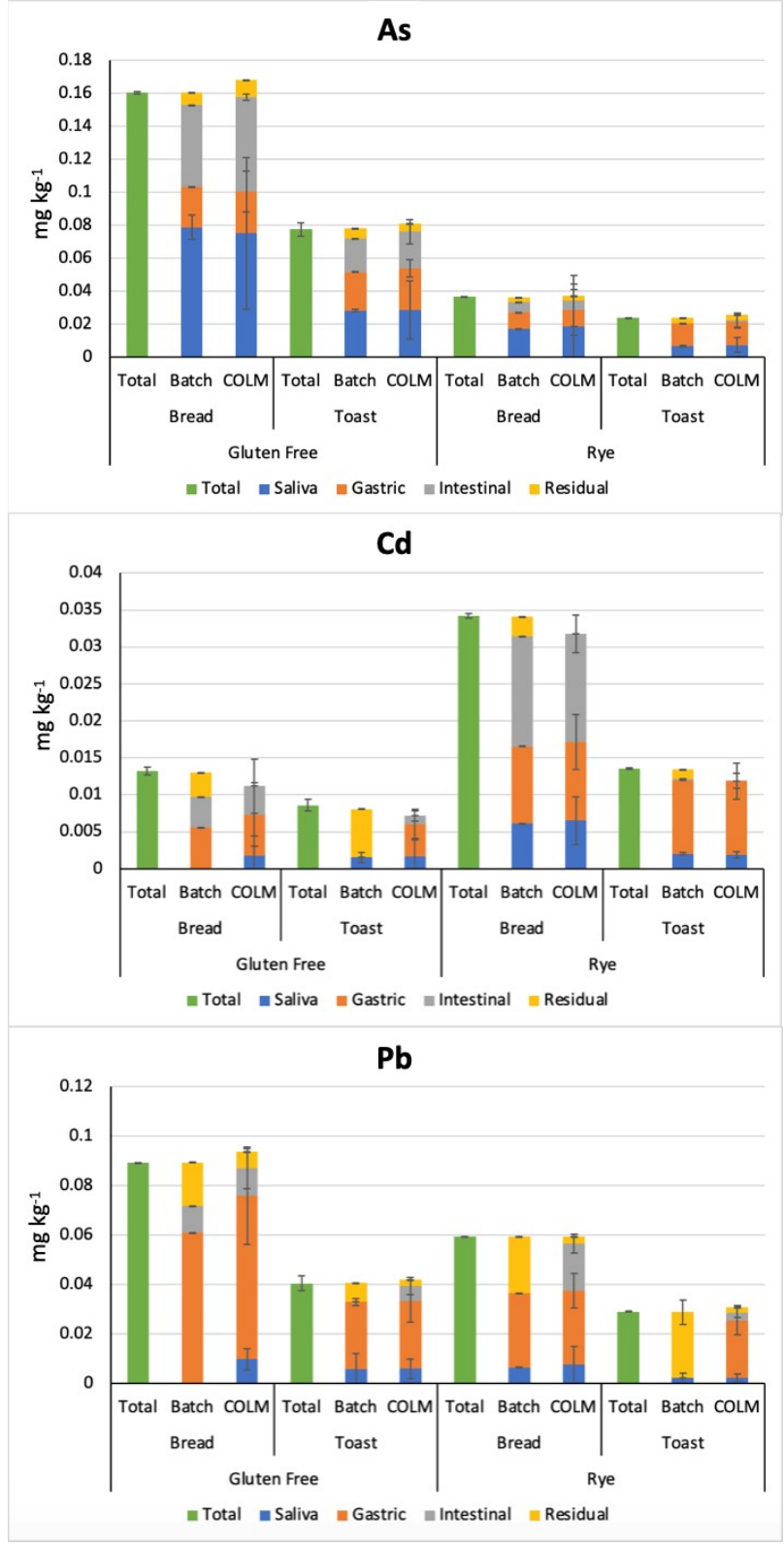

Fig. 1 Total $(n=6)$, batch bioaccessibility $(n=5)$, and COLM bioaccessibility $(\mathrm{n}=5)$ concentrations of $\mathrm{As}, \mathrm{Cd}$, and $\mathrm{Pb}\left(\mathrm{mg} \mathrm{kg}^{-1}\right)$ in GF, rye bread, and toast samples.

occur when foods undergo processes, such as toasting. Although cooking time, temperature, and water content have a significant impact on the complexation and volatilization of elements with organic components in the food, studies have found that higher temperatures during cooking (particularly when frying or grilling at around $250^{\circ} \mathrm{C}$ ) can cause losses of $\mathrm{As}, \mathrm{Cd}$, and $\mathrm{Pb} .{ }^{37,38}$ Additionally, this volatilization may be enhanced by the salt $(\mathrm{NaCl})$ content, as chlorides of these PTEs are volatile. In terms of bioaccessibility, As was mainly leached into the saliva phase for all samples (except the rye toasts where it was mainly 


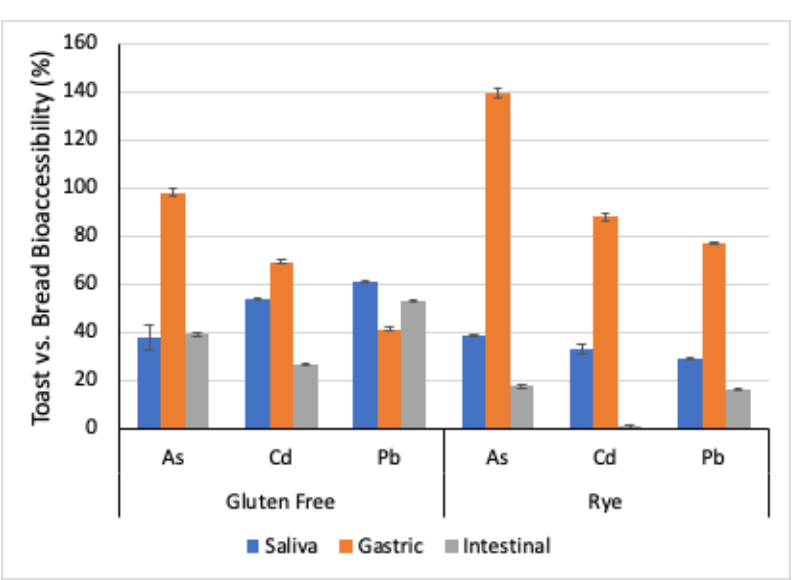

Fig. 2 Fraction of $\mathrm{As}, \mathrm{Cd}$, and $\mathrm{Pb}$ released by each gastrointestinal fluid from toast versus that released from bread, expressed as a percentage of the latter $(\mathrm{n}=5)$.

leached into the gastric phase), which indicated that it might be more labile in these samples than in other PTEs. This is consistent with other results for As in rice, where washing significantly reduced the amount of As that was bioaccessible. ${ }^{22}$ $\mathrm{Cd}$ was mainly leached into the gastric phase, although the rye bread samples exhibited more leaching into the intestinal phase. The batch method could not leach Cd into the gastric or intestinal phases, leading to a significant portion remaining in the residual. The COLM residuals for $\mathrm{Cd}$ were below the detection limit of the method $\left(<0.08 \mathrm{mg} \mathrm{kg}^{-1}\right)$ as the majority of $\mathrm{Cd}$ was leached into the gastric phase (except in rye bread, where leaching mainly occurred into the intestinal phase). $\mathrm{Pb}$ was mainly leached into the gastric phase across all samples, with a very small amount leached into the saliva or intestinal phase.

To visualize the effect of toasting on bioaccessibility, the amount of each PTE released by a given gastrointestinal reagent from toast was expressed relative to the amount released from the corresponding bread in Fig. 2. As can be seen, most of the fraction released by gastric juice remained after toasting whereas the fractions released by saliva and, especially, intestinal fluid significantly decreased after toasting. This observation is counter-intuitive, as one might have expected the most accessible fraction (i.e. that released by saliva) to be lost first. These results indicate that volatility does not correlate with bioaccessibility.

Preliminary risk assessment. Using the COLM bioaccessibility concentrations, the TDIs for each element, an average adult body weight of $70.7 \mathrm{~kg}$, and the reported serving size for each bread, and a preliminary risk assessment was conducted to determine how many slices would put an average adult over their TDI threshold. As is shown in Table 1, an adult is most likely to reach their TDI for As by eating only three slices of GF bread. Toasting lowers this effect by approximately 2.3 times, but a diet consisting largely of GF alternatives could push an adult above their As TDI. Regarding As in the rye samples, there was less risk, and 12 bread or 19 toast slices would be required to push an adult
Table 1. Realistic Per-slice Risk Assessment of GF, Rye Bread, and Toast Samples for As, Cd, and Pb Using Guidance Tolerable Daily Intake (TDI) Levels and Bioaccessibility Concentrations from the COLM

\begin{tabular}{lcccc}
\hline GF Slice Size* & $42 \mathrm{~g}$ & & & \\
Rye Slice Size* & $50 \mathrm{~g}$ & & & \\
Average Adult Body & 70.7 & $\mathrm{As}$ & $\mathrm{Cd}$ & $\mathrm{Pb}$ \\
Weight (bw) & $\mathrm{kg}$ & & & \\
\hline TDI (mg kg-bw-1 day-1) & & $0.0003^{18}$ & $0.0008^{17}$ & $0.0005^{17}$ \\
GF Bread (slices) & 3 & 76 & 10 \\
GF Toast (slices) & & 7 & 143 & 21 \\
Rye Bread (slices) & & 12 & 33 & 13 \\
Rye Toast (slices) & & 19 & 90 & 25 \\
\hline
\end{tabular}

*As indicated by packaging nutritional information.
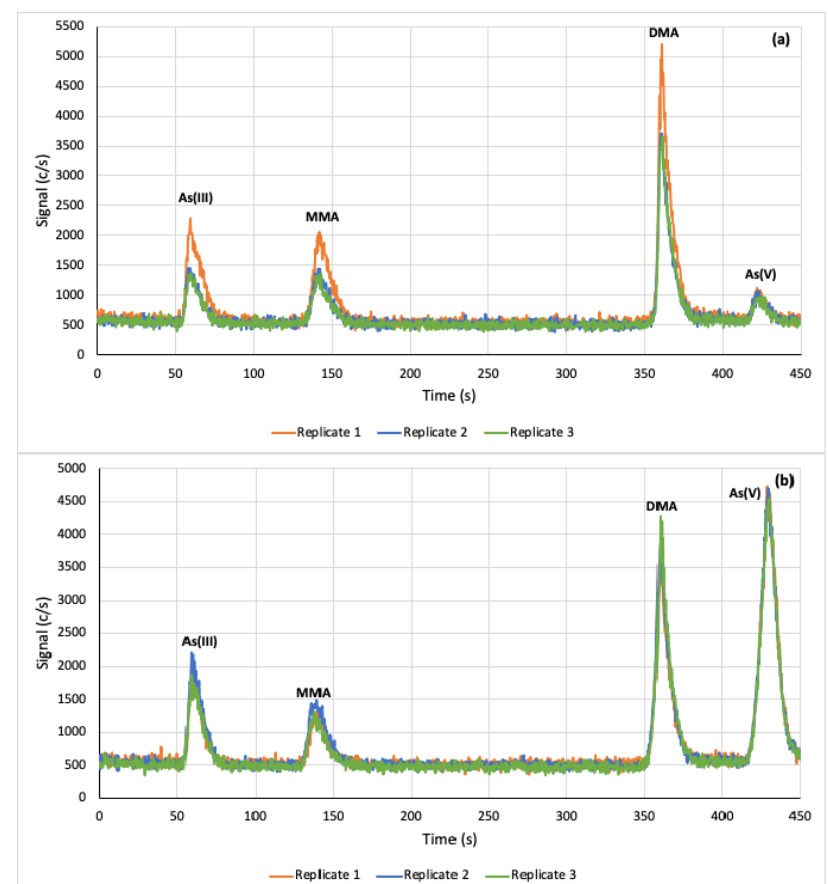

Fig. 3 Chromatograms obtained while monitoring As for triplicate injections of a (a) saliva leachate (5-fold diluted in DDW) and (b) gastric juice leachate (undiluted) from gluten free toast. MMA and DMA stand for monomethyl arsonic acid and dimethylarsinic acid respectively.

above their TDI. However, the recommended serving size for the GF bread was 2 slices and the rye bread was $1 / 9^{\text {th }}$ loaf (estimated to be 1 slice based on weight). Therefore, an adult eating one recommended serving of these alternative breads daily would not be in exceedance of their TDI for any PTEs studied. Although children could be at a higher risk if they are consuming these breads (as they have a lower bodyweight), adults are more likely to be consuming a diet of alterative breads and are therefore more relevant in this study. ${ }^{4}$ In any case, as is evident from Fig. 1, the bioaccessibilities of all PTEs studied were close to $100 \%$. A 


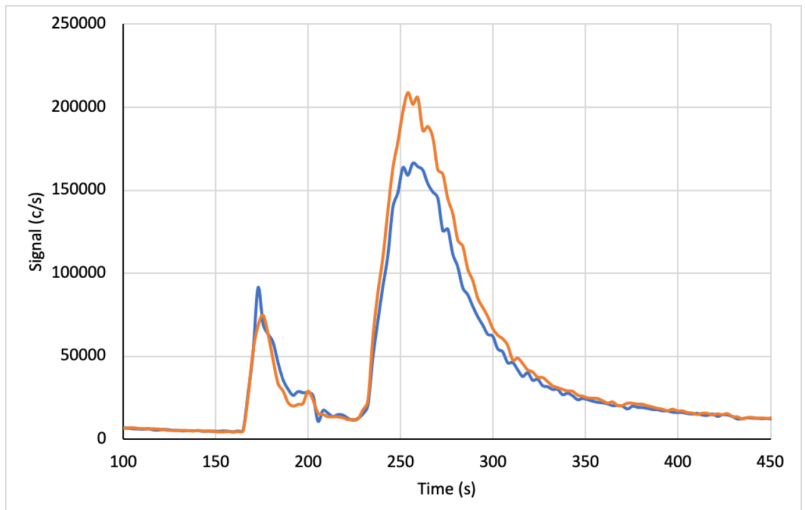

Fig. 4 Time-resolved leaching profile for duplicate $\mathrm{Pb}$ measurements in the gastric phase of rye bread samples indicating two elution peaks.

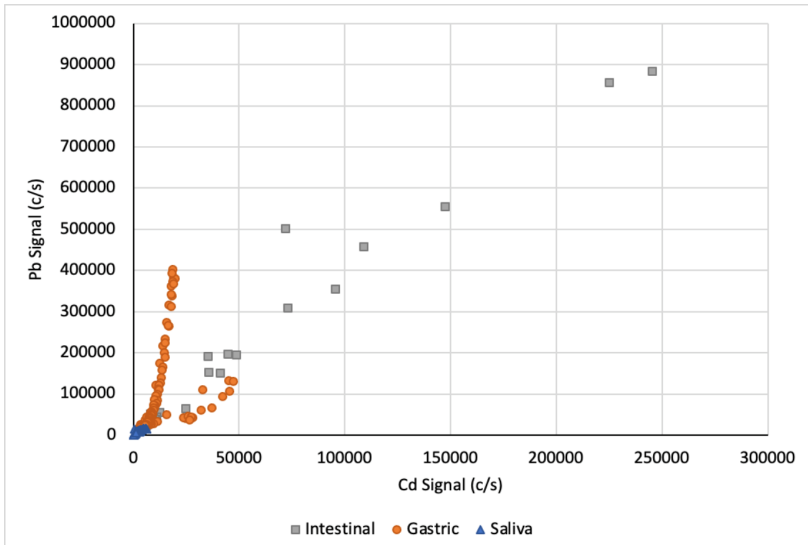

Fig. 5 Correlation plot of counts-per-second (c/s) $\mathrm{Cd}$ vs. $\mathrm{Pb}$ gastrointestinal leaching profiles in a rye bread sample. Intestinal (grey squares) and saliva (blue triangles) leaching fall closely onto one line, whereas gastric leaching (orange circles) indicates two distinct sources.

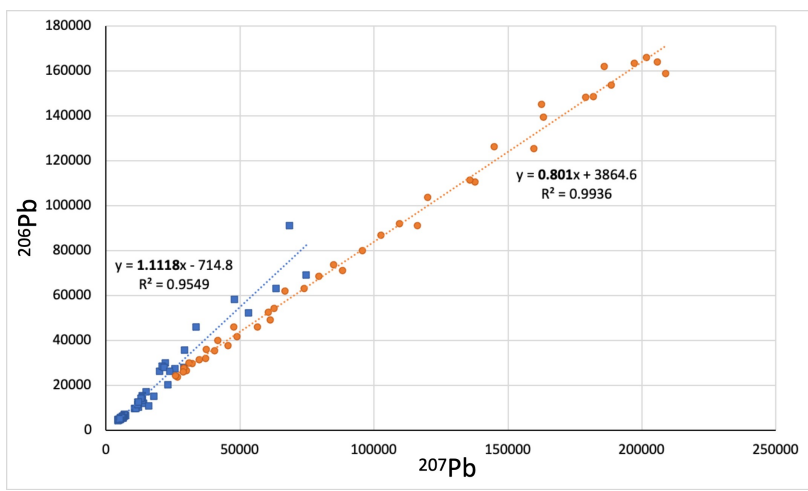

Fig. 6 An example of ${ }^{206} \mathrm{~Pb} /{ }^{207} \mathrm{~Pb}$ ratio determination using the correlation method for the two gastric sources identified in the rye bread. Source 1 is indicated in blue squares and source 2 is indicated in orange circles.

preliminary speciation analysis of the bio-accessible fractions in saliva and gastric juice in Fig. 3 revealed that a significant portion of As is in inorganic form (i.e. As(III) and $\mathrm{As}(\mathrm{V})$ ), a class I carcinogen. This preliminary study thus indicates that more GF alternatives should be investigated to see if a representative GF diet could put individuals at risk for PTE intake. Future work should also include a comprehensive speciation analysis of the bioaccessible fractions to better characterize the risk from As during the consumption of GF breads.

Source apportionment. Fig. 4 shows the temporal profile for $\mathrm{Pb}$ during leaching of rye bread by gastric juice. Two peaks are evident, indicating two $\mathrm{Pb}$-containing components or species dissolving separately. To ascertain if they came from the same source, an approach that is uniquely afforded by the COLM was used. Indeed, by plotting one PTE leaching profile against another, an indication of the sources of these PTEs can potentially be elucidated. If the PTEs come from the same source, then they will dissolve together and correlate, i.e. plot along a single line. If there are multiple PTE sources, additional correlations may result. Fig. 5 demonstrates an example of this with the correlation of $\mathrm{Cd} \mathrm{vs} . \mathrm{Pb}$ signals in counts-per-second (c/s) for the three gastrointestinal phases in a rye bread sample. In the intestinal phase, $\mathrm{Cd}$ and $\mathrm{Pb}$ leach very similarly, and their points lie along one line. The saliva phase also falls along one line. However, in the gastric phase, $\mathrm{Pb}$ seems to be leaching from two separate sources: one that likely contains more $\mathrm{Pb}$ than $\mathrm{Cd}$ and from which $\mathrm{Pb}$ dissolves faster than $\mathrm{Cd}$, resulting in the nearly vertical line near the $y$-axis; and another that is similar to the source leached in saliva and intestinal juice, as the correlation essentially follows the same line. To further confirm this, $\mathrm{a} \mathrm{Pb}$ isotope ratio analysis of these samples was performed with the time-resolved leaching information from the COLM and isotopic information provided by ICPMS.

$\mathrm{Pb}$ isotope ratio analysis. $\mathrm{Pb}$ isotope ratios are useful for source apportionment and can indicate the $\mathrm{Pb}$ source. $\mathrm{Pb}$ ratios were calculated using two methods. In the first method, the point-by-point average $\mathrm{Pb}$ isotope ratio across the top half of each peak in Fig. 4 was calculated following a protocol similar to that used in a previous work. ${ }^{25}$ Because this method can be sensitive to instrumental fluctuations, the approach proposed by Epov et al. was also tested. ${ }^{39}$ By plotting the isotopic $\mathrm{Pb}$ signals for the points that lie along each line in Fig. 5, the slope of the linear portion is the isotope ratio of the $\mathrm{Pb}$ from each source. An example of the ${ }^{206} \mathrm{~Pb} / 207 \mathrm{~Pb}$ ratio determination using this method is shown in Fig. 6 for the two gastric sources identified in rye bread.

The results for the ${ }^{206} \mathrm{~Pb} /{ }^{207} \mathrm{~Pb}$ ratio for all gastrointestinal phases across both methods are presented in Table 2 . Within error, there is no significant difference between the ratios obtained using both methods, except for the ${ }^{206} \mathrm{~Pb} /{ }^{207} \mathrm{~Pb}$ ratio in the first gastric source from the rye bread, which was significantly different from the other isotope ratios according to a Student's $\mathrm{t}$-test at the $95 \%$ confidence interval. In the literature, for $\mathrm{Pb}$ 
Table 2. Pb Isotope Ratios in All Gastrointestinal Phases Calculated Using Two Methods for GF and Rye Breads, and TEL Literature Reference Values

\begin{tabular}{|c|c|c|c|c|c|}
\hline \multirow{2}{*}{\multicolumn{2}{|c|}{$\begin{array}{l}\text { Isotope ratio } \\
\text { TEL Ratio }^{39} \\
\end{array}$}} & \multicolumn{2}{|c|}{${ }^{206} \mathrm{~Pb} /{ }^{207} \mathrm{~Pb}$} & \multicolumn{2}{|c|}{${ }^{208} \mathrm{~Pb} /{ }^{206} \mathrm{~Pb}$} \\
\hline & & \multicolumn{2}{|c|}{1.2} & \multicolumn{2}{|c|}{2.05} \\
\hline Sample & Phase & Point-by-Point Average & Correlation Ratio & Point-by-Point Average & Correlation Ratio \\
\hline \multirow{4}{*}{ GF Bread } & Saliva & $0.872 \pm 0.066(\mathrm{n}=40)$ & $0.883 \pm 0.053(n=32)$ & $\begin{array}{l}2.23 \pm 0.21 \\
(n=40)\end{array}$ & $\begin{array}{l}1.87 \pm 0.51 \\
(\mathrm{n}=32)\end{array}$ \\
\hline & Gastric & $0.796 \pm 0.019(\mathrm{n}=91)$ & $\begin{array}{l}0.7930 \pm 0.0026 \\
(\mathrm{n}=57)\end{array}$ & $\begin{array}{l}2.416 \pm 0.075 \\
(n=91)\end{array}$ & $\begin{array}{l}2.4099 \pm 0.0081 \\
(\mathrm{n}=57)\end{array}$ \\
\hline & Intestinal 1 & $\begin{array}{l}0.837 \pm 0.029 \\
(n=27)\end{array}$ & $\begin{array}{l}0.797 \pm 0.015 \\
(n=42)\end{array}$ & $\begin{array}{l}2.31 \pm 0.11 \\
(n=27)\end{array}$ & $\begin{array}{l}2.368 \pm 0.057 \\
(n=42)\end{array}$ \\
\hline & Intestinal 2 & $\begin{array}{l}0.872 \pm 0.036 \\
(n=42)\end{array}$ & $\begin{array}{l}0.8577 \pm 0.0091 \\
(n=28)\end{array}$ & $\begin{array}{l}2.200 \pm 0.087 \\
(n=42)\end{array}$ & $\begin{array}{l}2.236 \pm 0.038 \\
(n=28)\end{array}$ \\
\hline \multirow{4}{*}{ Rye Bread } & Saliva & $\begin{array}{l}0.893 \pm 0.057 \\
(n=21)\end{array}$ & $\begin{array}{l}0.865 \pm 0.073 \\
(n=59)\end{array}$ & $\begin{array}{l}2.20 \pm 0.17 \\
(n=21)\end{array}$ & $\begin{array}{l}1.978 \pm 0.059 \\
(n=59)\end{array}$ \\
\hline & Gastric 1 & $\begin{array}{l}1.15 \pm 0.17 \\
(\mathrm{n}=16)\end{array}$ & $\begin{array}{l}1.112 \pm 0.033 \\
(\mathrm{n}=57)\end{array}$ & $\begin{array}{l}2.02 \pm 0.29 \\
(\mathrm{n}=16)\end{array}$ & $\begin{array}{l}2.053 \pm 0.060 \\
(\mathrm{n}=57)\end{array}$ \\
\hline & Gastric 2 & $\begin{array}{l}0.876 \pm 0.056 \\
(\mathrm{n}=57)\end{array}$ & $\begin{array}{l}0.801 \pm 0.010 \\
(n=43)\end{array}$ & $\begin{array}{l}2.23 \pm 0.15 \\
(\mathrm{n}=57)\end{array}$ & $\begin{array}{l}2.412 \pm 0.031 \\
(n=43)\end{array}$ \\
\hline & Intestinal & $\begin{array}{l}0.87 \pm 0.33 \\
(n=15)\end{array}$ & $\begin{array}{l}0.888 \pm 0.037 \\
(n=28)\end{array}$ & $\begin{array}{l}2.16 \pm 0.55 \\
(n=15)\end{array}$ & $\begin{array}{l}2.190 \pm 0.098 \\
(n=28)\end{array}$ \\
\hline
\end{tabular}

source apportionments, the ${ }^{206} \mathrm{~Pb} /{ }^{207} \mathrm{~Pb}$ ratio reflects TEL added to gasoline in North America, which was manufactured from one ore source in Mississipi. ${ }^{31,34-36}$ This was additionally confirmed by the ${ }^{208} \mathrm{~Pb} /{ }^{206} \mathrm{~Pb}$ ratios in Table 2 , where only the ${ }^{208} \mathrm{~Pb} /{ }^{206} \mathrm{~Pb}$ ratio in the first gastric peak corresponds to the reference value of 2.05 for TEL. Although no CRM with $\mathrm{Pb}$ isotope ratio values was available for this matrix, given that $\mathrm{Pb}$ is a high-mass element that is usually free of spectroscopic interference and that significantly different isotope ratios were measured in the same matrix from the same sample, accurate isotope ratios can be inferred. To the best of our knowledge, this is the first time $\mathrm{Pb}$ apportionment has been performed alongside bioaccessibility for bread samples. This unique information has been observed previously in corn bran when samples were analyzed using the COLM with a point-by-point average $\mathrm{Pb}$ ratio determination. ${ }^{25}$ Batch methods of bioaccessibility analysis do not provide this information because the continuous mixing equilibrates the leaching phases and sources. Furthermore, a correlation-based calculation of $\mathrm{Pb}$ isotope ratios is less sensitive to instrumental fluctuations that result from time-resolved analysis and provides more precise ratios in many cases in Table 2. This highlights the importance of bioaccessibility analysis, particularly with the COLM, where kinetic leaching profiles can be further examined through method's time-resolved spectral analysis.
Effect of toasting on source apportionment. Interestingly, the first $\mathrm{Pb}$ peak observed in the gastric juice leachate from rye bread in Fig. 4 completely disappeared after toasting (see Fig. S1). The ${ }^{206} \mathrm{~Pb} /{ }^{207} \mathrm{~Pb}$ and ${ }^{208} \mathrm{~Pb} /{ }^{206} \mathrm{~Pb}$ isotope ratios measured in the gastric juice leachate from rye toast were $0.8111 \pm 0.0027$ and $2.3588 \pm$ 0.0076 respectively $(n=195)$. These ratios are not significantly different from those measured in the second source (second peak in Fig. 4) from rye bread according to a Student's t-test at the $95 \%$ confidence level. Hence, toasting resulted in the volatilization of the TEL source, indirectly confirming TEL as one source of $\mathrm{Pb}$ in rye bread.

\section{CONCLUSIONS}

The determination of $\mathrm{As}, \mathrm{Cd}$, and $\mathrm{Pb}$ levels in GF and rye bread and toast samples indicated that toasting lowered all PTE concentrations by 1.5 to 2.5 times. This was likely because of the volatilization of elements during the toasting process. As was leached mainly into the saliva phase, and Cd was mostly leached into the gastric in terms of bioaccessibility. Lead was mainly leached into the gastric phase with small amounts into the saliva or intestinal phases. Percent bioaccessibility was compared between the batch and COLM, and mass balance was performed. There was no statistically significant difference between the total 
and either bioaccessibility method concentrations at the $95 \%$ confidence interval. Toasting had little effect on the fraction released by gastric juice but substantially decreased the amount leached by saliva and especially intestinal fluid. A per-slice risk assessment indicated that only three slices of the GF bread could put an adult in exceedance of their As TDI, although this serving exceeds the recommended serving size of the producer, and toasting lowered the risk by 2.3 times. Speciation analysis of the saliva and gastric juice leachates from GF toast for As revealed a significant portion in the As(III) and As(V) forms. Rye bread and all other PTEs indicated little to no risk in isolation. Further work will investigate whether a representative GF diet could put individuals at risk of PTE intake. The COLM allowed for $\mathrm{Pb}$ source apportionment through correlation plots of PTE leaching profiles and a novel $\mathrm{Pb}$ isotope ratio analysis method. This identified the gastric-mobile $\mathrm{Pb}$ in the rye bread as coming from TEL, historically used in gasoline in North America. Interestingly, this source disappeared upon toasting rye bread. Future work will endeavor to analyze additional types of breads and GF products using bioaccessibility analysis, including a comprehensive speciation analysis in the case of As, and PTE sourcing to characterize better the health benefits and risks of these alternative foods.

\section{ASSOCIATED CONTENT}

\section{Supporting Information}

The Supporting Information (Fig S1, Fig S2, Table S1) is available at www.at-spectrosc.com/as/home

\section{AUTHOR INFORMATION}

\author{
Corresponding Author \\ * D. Beauchemin \\ Email address: diane.beauchemin@queensu.ca
}

\section{Notes}

The authors declare no competing financial interest.

\section{ACKNOWLEDGMENTS}

The authors would like to gratefully acknowledge the Natural Sciences and Engineering Research Council of Canada for funding (RGPNM 39487-2018). AK also thanks Queen's University School of Graduate Studies for graduate awards.

\section{REFERENCES}

1. D. Peckenpaugh Snack Food Wholes. Bak., 2021

2. Statista Research Department, Bread and bakery products in Europe - Statistics and Facts | Statista, 2021.

3. H. S. Kim, K. G. Patel, E. Orosz, N. Kothari, M. F. Demyen, N. Pyrsopoulos, and S. K. Ahlawat, JAMA Intern. Med., 2016, 176, 1716-1717. https://doi.org/10.1001/jamainternmed.2016.5254

4. A. Mudryj, A. Waugh, J. Slater, D. R. Duerksen, C. N. Bernstein, and N. D. Riediger, Can. Med. Assoc. J. Open, 2021, 9, E317-E323. https://doi.org/10.9778/cmajo.20200082

5. The Lancet Editorials, Lancet Gastroenterol. Hepatol., 2016, 85, 1. https://doi.org/10.1016/S2468-1253(16)30087-5

6. G. Vici, L. Belli, M. Biondi, and V. Polzonetti, Clin. Nutr., 2016, 35, 1236-1241. https://doi.org/10.1016/j.clnu.2016.05.002

7. G. A. Gaesser and S. S. Angadi, J. Acad. Nutr. Diet., 2012, 112, 1330-1333. https://doi.org/10.1016/j.jand.2012.06.009

8. B. Niland and B. D. Cash, Gastroenterol. Hepatol., 2018, 14, 82-91. https://www.ncbi.nlm.nih.gov/pubmed/29606920

9. I. Shtangeeva, E. Steinnes, and S. Lierhagen, Environ. Exp. Bot., 2011, 70, 259-265. https://doi.org/10.1016/j.envexpbot.2010.09.013

10. R. A. Althobiti and D. Beauchemin, J. Anal. At. Spectrom., 2018, 33, 642-648. https://doi.org/10.1039/c8ja00047f

11. N. W. Sadiq, "Multi-Elemental Risk Assessment of Rice Products Using On-Line Continuous Leaching and Ion Exchange Chromatography Coupled to Inductively Coupled Plasma Mass Spectrometry for the Speciation Analysis of Bio-Accessible Elements", Thesis, Queen's University, Kingston, ON, Canada, 2016.

12. J. C. Ng, A. Juhasz, E. Smith, and R. Naidu, Environ. Sci. Pollut. Res., 2015, 22, 8802-8825. https://doi.org/10.1007/s11356-013-1820-9

13. US Environmental Protection Agency, Standard Operating Procedure for an In Vitro Bioaccessibility Assay for Lead and Arsenic in Soil, Washington D.C., 2017.

14. BARGE - INERIS, "UBM procedure for the measurement of inorganic contaminant bioaccessibility from solid matrices", Report, Bioaccessibility Research Group of Europe (BARGE), Nottingham, UK, 2011, 1-10.

15. S. Bruce, B. Noller, V. Matanitobua, and J. Ng, J. Toxicol. Environ. Heal. - Part A, 2007, 70, 1700-1711. https://doi.org/10.1080/15287390701434901

16. M. Intawongse and J. R. Dean, Trends Anal. Chem., 2006, 25 , 876-886. https://doi.org/10.1016/j.trac.2006.03.010

17. Health Canada, Federal Contaminated Site Risk Assessment in Canada. Part II: Health Canada Toxicological Reference Values (TRVs) Version 3.0, 2021.

18. S. D. Branch, Rationale for the Development of Soil and Ground Water Standards for Use At, Toronto (ON), 2011.

19. European Food Safety Authority, EFSA J., 2009, 10, 1351. https://doi.org/10.2903/j.efsa.2009.1351

20. N. S. Horner and D. Beauchemin, Anal. Chim. Acta, 2012, 717, 1-6. https://doi.org/10.1016/j.aca.2011.12.049 
21. R. A. Althobiti, N. W. Sadiq, and D. Beauchemin, Food Chem., 2018, 257, 230-236. https://doi.org/10.1016/j.foodchem.2018.03.015

22. N. S. Horner and D. Beauchemin, Anal. Chim. Acta, 2013, 758, 28-35. https://doi.org/10.1016/j.aca.2012.11.011

23. A. Leufroy, L. Noël, D. Beauchemin, and T. Guérin, Anal. Bioanal. Chem., 2012, 402, 2849-2859. https://doi.org/10.1007/s00216-012-5774-4

24. A. Leufroy, L. Noël, D. Beauchemin, and T. Guérin, Food Chem., 2012, 135, 623-633. https://doi.org/10.1016/j.foodchem.2012.03.119

25. M. Y. Chu and D. Beauchemin, J. Anal. At. Spectrom., 2004, 19, 1213-1216. https://doi.org/10.1039/b403215b

26. R. P. Lamsal and D. Beauchemin, Anal. Chim. Acta, 2015, 867, 9-17. https://doi.org/10.1016/j.aca.2015.02.047

27. M. Silva, K. Kyser, C. Oates, and D. Beauchemin, J. Geochemical Explor., 2007, 94, 30-42. https://doi.org/10.1016/j.gexplo.2007.05.002

28. R. A. Althobiti and D. Beauchemin, J. Anal. At. Spectrom., 2021, 36, 622-629. https://doi.org/10.1039/d0ja00447b

29. R. M. Ellam, Sci. Total Environ., 2010, 408, 3490-3492. https://doi.org/10.1016/j.scitotenv.2010.03.037

30. D. Meza-Figueroa, B. González-Grijalva, F. Romero, J. Ruiz, M. Pedroza-Montero, C. I. Del Rivero, M. Acosta-Elías, L. Ochoa-Landin and S. Navarro-Espinoza, Sci. Total
Environ., 2018, 630, 1596-1607.

https://doi.org/10.1016/j.scitotenv.2018.02.285

31. W. T. Sturges and L. A. Barrie, Nature, 1987, 329, 144-146. https://doi.org/10.1038/329144a0

32. Y. Erel, A. Veron, and L. Halicz, Geochim. Cosmochim. Acta, 1997, 61, 4495-4505. https://doi.org/10.1016/S0016-7037(97)00353-0

33. K. E. Smith, D. Weis, S. R. Scott, C. J. Berg, Y. Segal, and P. Claeys, Environ. Res., 2021, 195, 110800. https://doi.org/10.1016/j.envres.2021.110800

34. A. M. Scheuhammer and D. M. Templeton, Ecotoxicology, 1998, 7, 37-42. https://doi.org/10.1023/A:1008855617453

35. A. M. Scheuhammer, D. E. Bond, N. M. Burgess, and J. Rodrigue, Environ. Toxicol. Chem., 2003, 22, 2585-2591. https://doi.org/10.1897/02-361

36. M. M. Larsen, J. S. Blusztajn, O. Andersen, and I. Dahllöf, J. Environ. Monit., 2012, 14, 2893-2901. https://doi.org/10.1039/c2em30579h

37. V. Devesa, D. Vélez, and R. Montoro, Food Chem. Toxicol., 2008, 46, 1-8. https://doi.org/10.1016/j.fct.2007.08.021

38. G. Perello, R. Martí-Cid, J. M. Llobet, and J. L. Domingo, J. Agric. Food Chem., 2008, 56, 11262-11269. https://doi.org/10.1021/jf802411q

39. V. N. Epov, S. Berail, M. Jimenez-Moreno, V. Perrot, C. Pecheyran, D. Amouroux, and O. F. X. Donard, Anal. Chem. 2010, 82, 5652-5662. https://doi.org/10.1021/ac100648f 